УДК 34 (510) (091)

DOI 10.18101/2658-4409-2019-4-24-31

\title{
ТРАДИЦИИ И ПРАВОВАЯ КУЛЬТУРА ДРЕВНЕГО КИТАЯ
}

\section{(C) Ван Чжихуа}

доктор юридических наук, профессор,

Институт сравнительного правоведения,

Политико-юридический университет Китая

Китай, 100088, г. Пекин, район Хайдянь, ул. Ситучэнлуд, 25

E-mail: imwang333@sina.com

Статья посвящается анализу китайской традиционной правовой культуры. С точки зрения автора, признаки традиционной правовой культуры в Китае состоят в следующем: единственный источник права - воля государей; развитое публичное право; гражданские споры разрешены уголовными наказаниями; сословная структура общества; развитая система гражданского чиновничества; отсутствие профессиональных судей и т. д. А восточное самодержавие оказало существенное влияние на формирование китайской традиционной правовой культуры.

Ключевые слова: история права; правовая культура; источник права; публичное право; традиции Китая.

\section{Для цитирования}

Ван Чжихуа. Традиции и правовая культура Древнего Китая // Вестник Бурятского государственного университета. Юриспруденция. 2019. Вып. 4. C. 24-31.

Китайская цивилизация - одна из древнейших в мире. Ее возраст может составлять 5000 лет, при этом имеющиеся письменные источники охватывают период не менее 3500 лет. Наличие систем административного управления, которые совершенствовались сменявшими друг друга династиями, раннее освоение крупнейших аграрных очагов в бассейнах рек Хуанхэ и Янцзы стали преимуществами китайского государства, экономика которого основывалась на развитом земледелии, по сравнению с соседями-кочевниками и горцами [1]. Еще более укрепило китайскую цивилизацию введение конфуцианства в качестве государственной идеологии (І в. до н. э.) и единой системы письменностей. 
Ван Чжихуа. Традиции и правовая культура Древнего Китая

История Китая отличается не только древностью, господствовало самодержавие, использовалась единая государственная идеология - конфуцианство, а также существовала строгая иерархия общества.

Самодержавие означает единовластие. На верхушке пирамиды государственной власти находится монарх или какой-либо иной правитель (диктатор, деспот).

В эпоху Чжоу (XII-VIII вв. до н. э.) государи Китая начинают обожествляться (именуются сыном Неба, заместителем Неба), что сильно влияет на соотношение религии и светской власти. Государственная власть и религиозные объединения слились воедино, говоря иными словами, религия всегда подчиняется светским властям и даже существует как составная часть государственной идеологии. Религия никогда не приобретала возможности, благодаря которым могла бы противостоять власти государей.

Жители Поднебесной в древности были не равны в правах и общественном положении. Они делились на 4 сословия (仕农工商): 1) чиновники (знать); 2) крестьяне; 3) рабочие; 4) купцы.

Чиновники как господствующий класс не занимались физическим трудом. Их задачами были чтение книг и овладевание знаниями по управлению государством под руководством правителя. С точки зрения общества крестьянство было самым нужным сословием, поскольку сельское хозяйство было необходимо для всего общества в целом, особенно для чиновников, которых кормили крестьяне. Последние два сословия - paбочие и купцы - не принимались во внимание, считая, что роскошные изделия, подготовленные ремесленниками (рабочими), могут соблазнять государей развлечением и тем самым не дать им выполнять обязанности в правлении государством; а купцы, переводя товары с одного места на другое, ничего не творят. Более того, существовало презрительное отношение к ним со стороны чиновников [2]. Указанное обстоятельство позволяет объяснить, почему в Древнем Китае не развивались торговля и мореходство. На известном Шелковом пути отсутствовали китайские купцы. Существовал запрет переходить границу.

В соответствии с этой особенностью по характеру сословия Китая в древности были условно разделены на 2 класса: 1) чиновники (правители); 2) простой народ (поданные). То есть кто-то имеет власть, а кто-то ей подчиняется. Каждый находится в каком-либо звене властноподчиненных отношений. Везде и всюду кто-то подчиняется кому-то, например, в обществе в целом подчиняются монарху, в организации - 
начальнику, в общине - старейшине, в семье - ее главе (отцу, деду, прадеду и т. д).

В Древнем Китае не существовало дворянства, в отличие от Европы, Древнего Рима и феодального общества (патриции и плебеи), России (дворяне и крепостные). Структура общества и сословное устройство были не так стабильны, как на Западе. Человек мог изменить свою судьбу посредством сдачи государственного экзамена на должность чиновника. Экзамен состоял из таких дисциплин, как литература и публицистика, поэтому чиновники были одновременно поэтами и писателями. Таким образом, рядовой человек мог при должном старании и таланте изменить свою судьбу. То есть он мог путем сдачи государственного экзамена превратиться в чиновника, перейти из низшего сословия в высшее. Одаренные низшего сословия вместо классовой борьбы старались все силы отдавать карьерному росту. И динамика личного положения в известной мере тормозила развитие общества в целом. Люди стремились к захвату власти и перестали бороться за интересы своего класса. Мы видим, что в Китае династии сменяли друг друга, а прогрессивное движение не реализовывалось, а даже возникало попятное движение и застой, что доказано самой историей Китая.

Положение женщин в древности было более удручающим, чем положение мужчин, отсутствовало равноправие женщин и мужчин. До замужества женщина подчинялась отцу, после замужества - мужу, после смерти мужа - сыну. Кроме того, практиковалась полигамия (многоженство), а точнее, система «одна жена - несколько наложниц». Вступление в брак происходило с разрешения отца (главы семьи) и обязательно через свата как посредника. Инициировать расторжение брака (выдавать акт о расторжении брака) мог только муж [3]. Самым несправедливым отношением к женщинам был обычай «бинтования ног» в период с начала X до начала XX в. Целью «бинтования» было достижение ограничения действий и полная зависимость женщины от мужа, по всей вероятности, поддержание патриархального порядка. Женщины с изуродованными ногами объективно не имели возможности общаться с другими мужчинами. Это было полезно для образования стабильной семьи, а стабильность семьи положительно влияла на стабильность общества.

Китайская правовая культура, включая правовую систему и правосознание, сформировалась под воздействием вышеуказанных факторов.

А каковы особенности китайской правовой культуры? Во-первых, единственным источником права была воля государя. С точки зрения Гуань Чжуна, премьера-министра царства Вэй в период Чуньцю (Весна и 
Ван Чжихуа. Традиции и правовая культура Древнего Китая

Осень), государь издает законы, чиновники применяют законы, а народ подчиняется им [4]. То есть единственным законодателем является правитель, только он обладает такими полномочиями. Между тем в Древнем Риме существовало, как нам известно, несколько источников права, а именно: законы (решения комиций - народных собраний), постановления Сената (сенатусконсульты), решения судей (эдикты магистратов), конституции императоров, разъяснения юристов, правовые обычаи. Единственный источник права предопределил единственную в основном цель законодательства, направленную на охрану господства и подчинения, следовательно и характер публичного права.

Во-вторых, было развитое публичное право. В средневековом Китае существовало только уголовное (или по-другому - публичное) право, частное же право не было нормативно закреплено на законодательном уровне государства, как в Древнем Риме. Гражданско-правовые споры разрешались с помощью уголовно-правовых наказаний. В силу закона при неисполнении договорной обязанности должник привлечен к бамбукам и даже лишен свободы на срок до полутора лет. В наименовании первых законов Китая использовались понятия «наказание», «казнь».

Согласно «Книге документов» («Шу Цзин») в эпоху царства Вэй (с 445 по 225 в. до н. э.) была совершена первая систематизация китайских правовых документов. Ее осуществил министр Ли Куй (李悝). Был создан первый кодекс - «Фа Цзин», состоящий из 6 частей (пянь): 1) кража; 2) убийство; 3) содержание в тюрьме; 4) задержание преступников; 5) смешенные положения; 6) общие положения [5].

Bce 6 частей были посвящены преступлениям и наказаниям. Кодекс в измененном и дополненном виде применялся вплоть до последней китайской династии Цин.

О системе права Древнего Китая свидетельствуют также законы, принятые во времена династий Цинь (259-206 гг. до н. э.) и Хань (206 до н. э. 220 гг.). Фрагменты этих законов, дошедшие до нас, содержат нормы уголовного права. Вопросы частного права в них затрагивались только в связи с уголовным правом. Деление права на отрасли, включая деление права на частное и публичное, отсутствовало.

В уголовном уложении Древнего Китая была установлена стройная система наказаний, традиционно выделяли 5 видов наказаний: 1) смертная казнь (скручивание, сечение); 2) бессрочная ссылка; 3) срочная ссылка (1,5 года, 2 года, 2,5 года, 3 года); 4) тяжелое наказание бамбуковыми палками $(50,60,70,80,90,100$ раз); 5) легкое наказание бамбуковыми палками $(10,20,30,40,50$ раз) [6]. 
В сравнении с правом Древнего Китая древнеримский закон «12 таблиц» содержал положения как публичного, так и частного права. При этом частное право получило бо́льшее развитие, чем публичное.

B-третьих, гражданские споры разрешались путем уголовного наказания. Согласно положениям законов, за неисполнение договора или незаконное расторжение брака виновные могли получить наказание в виде ударов бамбуковыми палками и даже каторжных работ. Например, вступление женщины в брак в нарушение условий помолвки могло повлечь для ее отца лишение свободы до полутора лет.

В-четвертых, отсутствовало равенство перед законом и судом, что объясняется влиянием конфуцианства. Наказание за совершенное преступление, например убийство, определялось в зависимости от следующих обстоятельств: 1) мотив преступления; 2) объективная сторона преступления; 3) социальное положение преступника; 4) социальное положение потерпевшего.

Суровость наказания зависела от социального статуса преступника и потерпевшего. Одна ситуация, когда преступник - отец, а потерпевший сын. Но совершенно другая ситуация, когда преступник - сын, а потерпевший - отец. Если отец ударит сына, он не несет наказания. Однако если сын ударил отца, то его ждет наказание в виде каторжных работ или ударов бамбуковыми палками. Супруги наказывались так же: муж как отец, а жена как сын [7].

B-пятых, не поддерживалось разрешение споров судебным путем. Сторона обвинения и защитник, обратившиеся в суд, впоследствии не получали поддержку со стороны чиновников. Непопулярность судебного разрешения споров помимо пренебрежительного отношения чиновников к нему также объясняется нежеланием самих сторон подвергаться судебному произволу, в частности судебным поборам. Споры сторон рассматривались чиновниками. Также практиковалось разрешение споров через посредников. В случае отказа от услуг посредника, пользующегося хорошей репутацией, стороны могли подвергнуться общественному осуждению. Норма права имела факультативный по сравнению с другими социальными нормами характер, например по сравнению с нормами морали. Решение суда, основанное на нормах права, игнорировалось как средство защиты. В большинстве случаев споры не доходили до суда. Лишь незначительная часть споров рассматривалась в суде [8].

В-шестых, гражданско-правовые споры также разрешались во внесудебном порядке. Так, арбитром в семейных спорах выступал глава семьи, в т. ч. дальний родственник либо посторонний человек, обладающий жиз- 
Ван Чжихуа. Традиции и правовая культура Древнего Китая

ненным опытом и пользующийся авторитетом. Стороны обязаны были, дабы «не потерять лицо», согласиться с позицией посредника. Посредник разрешал семейные споры, основываясь на правилах поведения «ли» («礼»), означающих этикет, обряд, сложившейся практике решения подобных споров, собственном опыте. Обсуждение спора длилось до момента, когда его стороны наконец «созреют». Посредник не гнушался способами морального давления. Посредниками в иных частных спорах выступали представители местных элит, общин. Споры разрешались с учетом устоявшихся правил поведения местных общин, социального положения сторон [9].

В-седьмых, делался акцент на соблюдении материальной справедливости, а не на процессуальных правовых аспектах. В Древнем Китае отсутствовали профессиональные судьи. Суд вершили чиновники. В их полномочия входило разрешение споров, возникающих между подданными. Их задачи состояли в разрешении споров, формальная рациональность не входила в поле их внимания [10].

Следует отметить, что хотя в 2011 г. в КНР было провозглашено образование Специфической социалистической правовой системы, пережитки правовой традиции влияют на общественную жизнь и деятельность, особенно на правосознание людей. Например, тяжелые наказания в системе уголовного права; недостаточны гарантии прав человека; принципы верховенства закона и презумпции невиновности еще не установлены и т. д. Чтобы полностью создать модернизированную правовую систему в Китае, нужно преодолеть много проблем, как правовых, так и политических.

\section{Литература}

1. Регзенова Д. Б.-О. Сельское хозяйство в истории Древнего Китая // Вестник Бурятского государственного университета. Педагогика. Филология. Философия. 2011. № 8. С. 196.

2. Чен Шаовэн. Физиократизм и презрение с коммерцией в период воюющих царств // Ежемесячник науки. 1962. № 6. С. 53-58. 参见陈绍 闻：»战国时代的“重农轻商’思想》, 《学术月刊》1962 年第 6 期, 第 5358 页。

3. У Чаньчжин. Правовое положение женщин в Китае // Вестник Китайского женского института. 1997. № 4. С. 8. 巫昌祯 : »中国妇女的法律 地位》, 《中华女子学院学报》1997 年第 4 期, 第 8 页。

4. Гуанцзи. Законоведение. 《管子·任法》。 
5. Хе Чиньхуа. Новое исследование «Фа Цзин» // Правоведение. 1998. № 2. C. 15. 参见何勤华 : 》《法经》新考》, 《法学》1998 年第 2 期, 第 15 页。

6. Чэнь Дявэй. О системе 5 видов наказаний в Древнем Китае // Форум общественных наук. 2014. № 7. С. 244. 参见陈佳维 : »略论中国古代的五 刑制度》, 《社会科学论坛》2 014 年第 7 期, 第 244 页。

7. Чжан Ян. Правовая конфуцианция в эпоху династии Хан // Законность и общество. 2013. № 1. С. 9. 参见张艳 : »浅析汉朝法律的儒家化》,

《法制与社会》 2013 年第 1 期, 第 9 页。

8. Чжан Диньфан. Судебная традиция примирением споров и склонение на гармонию как китайский национальный дух // Народная законность. 2018. № 3. С. 84-85. 参见张晋藩 : »调解息讼的司法传统与崇尚和 谐的中华民族精神》，《人民法治》2018 年第 3 期, 第 84-85 页。

9. Сун Гуаньян. Исследование гармонических ценностей в китайском традиционном правопорядке: дис. ...д-ра ист. наук / Хэйлонцзянский университет. 2005. С. 184-194. 孙光妍 : »中国传统法之和谐价值研究》, 黑龙江大学法学院 2005 年博士学位论文, 第 184-194 页。

10. Сун Сяося. Сущностные мышления судей в традиционном Китае // Вестник Чжецзянского университета: гуманизм и общество. 2005. № 4. C. 5. 参见孙笑侠 : 》中国传统法官的实质性思维》, 《浙江大学学报（人 文社会科学版）》2005 年第 4 期，第5 页。 
Ван Чжихуа. Традиции и правовая культура Древнего Китая

\section{TRADITION AND LEGAL CULTURE OF ANCIENT CHINA}

Wang Zhihua

Doctor of Law, Professor,

Institute of Comparative Law, Political and Law University of China

25 Situchenlud, Haidian District, Beijing 100088, China

E-mail: imwang333@sina.com

The article is devoted to the analysis of Chinese traditional legal culture. From the author's point of view, the signs of traditional legal culture in China are as follows: the only source of law is the will of sovereigns; advanced public law; civil disputes resolved by criminal penalties; class structure of society; developed system of civil bureaucracy; lack of professional judges, etc. And the eastern autocracy had a significant impact on the formation of Chinese traditional legal culture

Keywords: history of law; legal culture; public law, source of law, traditions of China. 